\title{
Conservation of MAP kinase activity and MSP genes in parthenogenetic nematodes
}

\author{
Peter Heger*, Michael Kroiher, Nsah Ndifon and Einhard Schierenberg
}

\begin{abstract}
Background: MAP (mitogen-activated protein) kinase activation is a prerequisite for oocyte maturation, ovulation and fertilisation in many animals. In the hermaphroditic nematode Caenorhabditis elegans, an MSP (major sperm protein) dependent pathway is utilised for MAP kinase activation and successive oocyte maturation with extracellular MSP released from sperm acting as activator. How oocyte-to-embryo transition is triggered in parthenogenetic nematode species that lack sperm, is not known.

Results: We investigated two key elements of oocyte-to-embryo transition, MSP expression and MAP kinase signaling, in two parthenogenetic nematodes and their close hermaphroditic relatives. While activated MAP kinase is present in all analysed nematodes irrespective of the reproductive mode, MSP expression differs. In contrast to hermaphroditic or bisexual species, we do not find MSP expression at the protein level in parthenogenetic nematodes. However, genomic sequence analysis indicates that functional MSP genes are present in several parthenogenetic species.

Conclusions: We present three alternative interpretations to explain our findings. (1) MSP has lost its function as a trigger of MAP kinase activation and is not expressed in parthenogenetic nematodes. Activation of the MAP kinase pathway is achieved by another, unknown mechanism. Functional MSP genes are required for occasionally emerging males found in some parthenogenetic species. (2) Because of long-term disadvantages, parthenogenesis is of recent origin. MSP genes remained intact during this short intervall although they are useless. As in the first scenario, an unknown mechanism is responsible for MAP kinase activation. (3) The molecular machinery regulating oocyte-toembryo transition in parthenogenetic nematodes is conserved with respect to C. elegans, thus requiring intact MSP genes. However, MSP expression has been shifted to non-sperm cells and is reduced below the detection limits, but is still sufficient to trigger MAP kinase activation and embryogenesis.
\end{abstract}

\section{Background}

Throughout the animal kingdom, female gametes interrupt their development during oogenesis at various stages of meiosis. In response to external stimuli, this arrest is released, and oocyte maturation can take place. Then oocytes resume meiotic divisions, ovulate and get competent for fertilisation.

An important step during oocyte maturation of all animals is MAP kinase activation (reviewed in [1-3]). MAP kinases are ubiquitous serine-threonine protein kinases expressed in all eukaryotic cells $[4,5]$ and can be divided into five groups: The Erk1/2, p38, Jnk, Erk3/4, and Erk5 subfamilies [5]. They are activated by MAP kinase kinase-

* Correspondence: peter.heger@uni-koeln.de

1 Zoological Institute, University of Cologne, Zülpicher Strasse 47b, 50674 Köln, Germany

Full list of author information is available at the end of the article mediated dual phosphorylation on two distinct amino acids, Threonine and Tyrosine, in a T-X-Y motif of the activation loop [6]. Phosphorylation induces a rotation between the $\mathrm{N}$ - and $\mathrm{C}$-terminal domains that activates the kinase [7]. Activation is accompanied by a partial translocation to the nucleus [8,9] for phosphorylation of nuclear targets which mainly consist of transcription factors [5]. MAP kinase inactivation on the other hand is accomplished by MAP kinase phosphatases that specifically recognise and remove the dual phosphorylation [10].

There are MAP kinase orthologs from several subfamilies present in C. elegans. The Erk1/2 ortholog MPK-1 $[11,12]$ is the best studied representative and functions with its upstream cascade members LET-60 Ras (Rasrelated GTPase), LIN-45 Raf (MAP kinase kinase kinase) and MEK-2 (MAP kinase kinase) in vulval cell fate speci- 
fication, cell migration, and oocyte-to-embryo transition (reviewed in $[13,14]$ ).

MSP is a small basic protein of $\sim 15 \mathrm{kDa}$ (for review see [15]). It was first described as a major component of $C$. elegans sperm representing $15 \%$ of its total protein content [16]. In C. elegans, MSP comprises a large multigene family of about 50 highly conserved members [17] including more than 20 pseudogenes. The number of MSP genes detected in other nematodes is variable, from one in Ascaris suum to 1-13 in other mammalian intestinal parasites, 1-4 in filarial nematodes or 5-12 in plant and insect parasitic species $[18,19]$. MSP sequences are highly conserved in all nematodes [15]. All MSP genes of C. elegans are expressed at the same time and only during the terminal stages of spermatogenesis [20,21]. Restriction of MSP expression to male animals or their spermatocytes is also known for Oesophagostomum dentatum, Brugia malayi, Dictyocaulus viviparus and Ascaris suum [19,2224].

Besides its functions in sperm structure and motility [25-27], Greenstein and colleagues have shown that MSP has a range of extracellular signaling properties [28]. In oocytes, MSP signaling induces via the receptor tyrosine kinase VAB-1 the activation of MAP kinase and subsequently meiotic maturation and cell cycle progression $[28,29]$. It promotes muscle contractions in somatic gonadal sheath cells to facilitate ovulation [28]. In parallel, MSP signaling antagonises inhibitory signals from both, gonadal sheath cells and oocytes, that prevent meiotic maturation in the absence of sperm [29,30]. Gonadal sheath cells accordingly seem to function as the major initial sensor of MSP and control all MSP-dependent meiotic maturation events, potentially via multiple classes of G-protein-coupled receptors and communication through gap junctions [31].

These reports from the C. elegans literature highlight that resumption of meiosis and ovulation depend on sperm and sperm-released factors, thereby avoiding cost if no sperm is available. However, within the phylum Nematoda a variety of reproductive strategies exists. There is general consent that sexual reproduction is the ancestral and most widespread condition. In contrast, parthenogenetic reproduction and hermaphroditism are derived modes that have evolved within the phylum Nematoda several times independently $[32,33]$.

Whether or not the molecules regulating the C. elegans oocyte-to-embryo transition are functionally conserved in nematodes with different reproductive modes, is not known. Using C. elegans as a reference, we therefore wanted to investigate two key steps of oocyte-to-embryo transition, MAP kinase activation and MSP signaling, in parthenogenetic nematodes where sperm is absent.

\section{Results \\ MAP kinase genes are conserved in parthenogenetic nematodes}

As MAP kinase activation is mediated by sperm in C. elegans $[28,34]$, we reasoned that parthenogenetic nematodes that lack sperm might differ from hermaphrodites like C. elegans with respect to MAP kinase properties. To test this assumption, we cloned MAP kinase genes of the parthenogenetic nematode Acrobeloides nanus and of its close relative with hermaphroditic reproduction, Acrobeloides (herma), as well as the MAP kinase gene of a second parthenogenetic nematode, Diploscapter coronatus, a close relative of C. elegans (see Figure 1A; phylogeny after [35]). As only Erk1/2 MAP kinases are involved in oocyte maturation in C. elegans [34] and other animals [36-40], we wanted to ensure that the cloned MAP kinase sequences belong to this subfamily. Thus, we performed a phylogenetic analysis with a sequence set representing the five MAP kinase subfamilies. The resulting phylogenetic tree confirmed the placement of the newly isolated MAP kinase sequences to the Erk $1 / 2$ subfamily (Figure 1B). It further suggests that C. elegans MPK-2, whose function is not known so far [41], is a member of the Erk5 subfamily of MAP kinases. This is the least characterised mammalian MAP kinase pathway and known to be activated by oxidative stress and hyperosmolarity [42]. According to our phylogenetic tree, MPK-1 is the only Erk1/2 MAP kinase ortholog present in C. elegans suggesting that our cloned MAP kinase sequences, too, represent Erk1/2 orthologs with a possible role in oocyte maturation. Sequence comparison revealed that the MAP kinase sequences between phylogenetically related, but reproductively different pairs $A$. nanus/Acrobeloides (herma) and $C$. elegans/D. coronatus are slightly more similar to each other than sequence pairs derived from nematodes with identical reproduction ( $95 \%$ vs. $92 \%$, Figure $1 \mathrm{~A}, \mathrm{~B})$. The amino acid sequence of the entire activation loop is highly conserved in the MAP kinases of all nematode species considered here (Figure $1 \mathrm{C}$ ). In particular, T202 and Y204, which are phosphorylated during activation, are present in all MAP kinases and match the T-X-Y dual phosphorylation motif found in C. elegans MPK-1 and other Erk1/2 family members (Figure 1C). Thus, the considerable sequence conservation between hermaphroditic and parthenogenetic MAP kinases rejects the possibility of a specific alteration in parthenogenetic nematodes.

\section{MAP kinase activation is conserved in parthenogenetic nematodes}

Since the MAP kinase activation loop including the dual phosphorylation motif is conserved in parthenogenetic nematodes (Figure 1C), we wanted to know whether 


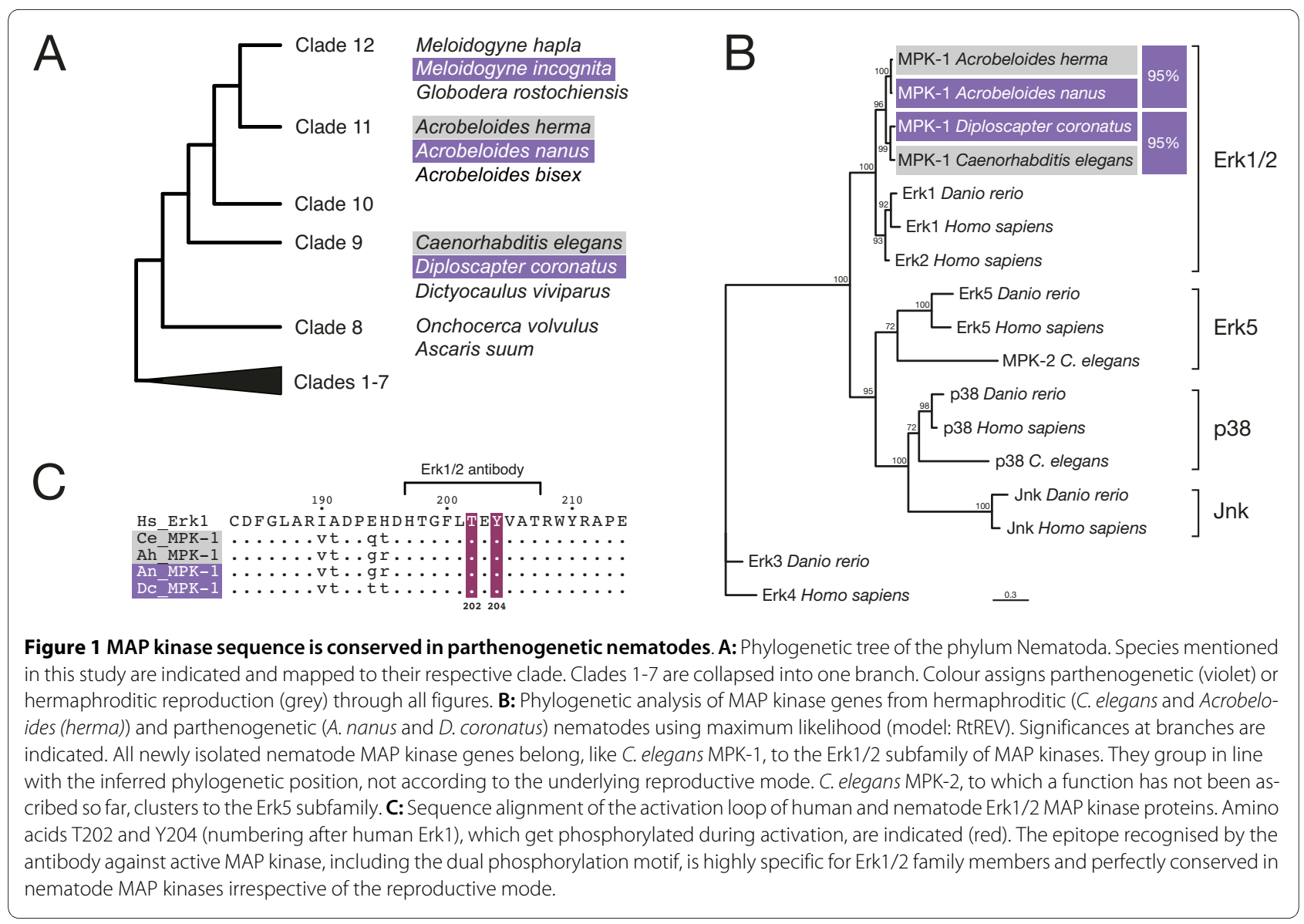

MAP kinase activation is detectable in these nematodes despite the lack of sperm. Therefore, we stained gonad preparations of our nematode set with a monoclonal antibody highly specific for the activation loop of diphosphorylated Erk1/2 MAP kinase. Our experiments revealed that MAP kinase is active in late-stage oocytes of all species regardless of the reproductive mode (Figure 2). MAP kinase stainings of $C$. elegans gonads confirmed already published data $[28,29,34]$ and gave a positive signal in proximal oocytes and the gonadal loop region (Figure $2 \mathrm{~A})$. This indicates that our experimental setup gives the anticipated results. As previously reported [34], we observed variable patterns of activated MAP kinase in the proximal oocytes of $C$. elegans (not shown), but also in the three Acrobeloides species. MAP kinase activation sometimes extended over three or four proximal oocytes $(-1$ to -4$)$, occasionally interrupted by a non-activated cell, or could be restricted to the -2 or -3 oocyte without a signal in -1. We noticed such staining patterns in 4/11 (A. nanus) and 11/22 cases (Acrobeloides (herma)). As an example, an unusual staining of the second and fourth, but not the first, oocyte from the Acrobeloides (bisex) gonad is shown (Figure 2E). It likely represents a snapshot shortly after activation of the -1 oocyte has been com- pleted. In contrast to other nematodes, exclusively the most proximal oocyte was stained in $D$. coronatus $(13 / 13$ cases; Figure 2I). This difference may be attributed to the shorter gonadal arms of $D$. coronatus where just a single or at most two large, yolk containing oocytes are present (Figure 2I, J) compared to a row of 5-10 in the other species.

Furthermore, the percentage of stained oocytes was considerably lower in $D$. coronatus than in C. elegans or in the Acrobeloides species (roughly $10 \%$ vs. $50 \%$ ). While C. elegans oocytes mature at a fast rate of one every 23 min [43], this interval is several times longer in D. coronatus (data not shown) giving a likely explanation for the less frequent staining of oocytes in this species.

We sometimes observed in the Acrobeloides species a more pronounced MAP kinase signal in the nuclei of latestage oocytes than in C. elegans (Figure 2C, E). This might be a consequence of the need for early transcription in Acrobeloides embryos [44] as compared to C. elegans [45].

MAP kinase activation is also required at an earlier stage in developing C. elegans oocytes, for the exit from pachytene of the first meiotic prophase [46], after which it is rapidly turned off. Therefore, a characteristic bipha- 

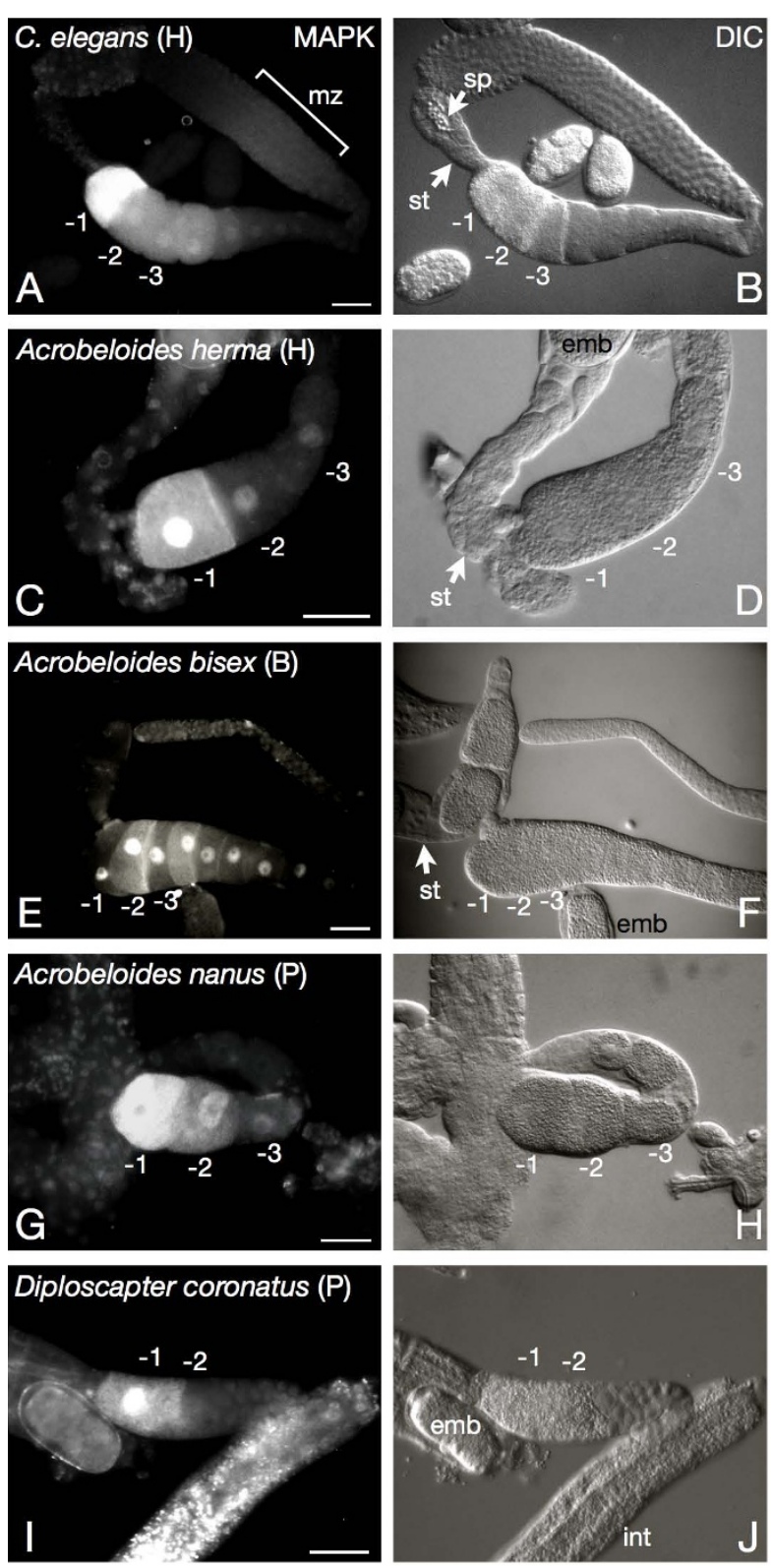

Figure 2 MAPK activation is conserved in parthenogenetic nematodes. Gonad preparations of parthenogenetic $(P)$, hermaphroditic $(H)$ and bisexual (B) nematode species stained for active MAP kinase (left panel; corresponding DIC picture: right panel). In all five nematode species with three different modes of reproduction, MAP kinase activation can be detected in proximal oocytes as described for the C. elegans system [28]. It is therefore independent of the reproductive strategy. In C. elegans, MAP kinase activation is biphasic and can also be observed in the meiotic zone (mz) of the syncytial gonad (panel A, bracket; [28,47]) The pronounced nuclear staining in Acrobeloides species might reflect early MAP kinase dependent gene expression. sp: sperm. st: spermatheca. int: intestine. emb: embryo. -1, -2,-3: proximal oocytes, -1 is most proximal. All gonads are oriented with proximal to the left. Bar: $20 \mu \mathrm{m}$. sic pattern of MAP kinase activation can be observed in the C. elegans germline (Figure 2A; $[28,47]$ ). Like C. elegans and other non-parthenogenetic nematodes the parthenogenetic species $A$. nanus and $D$. coronatus undergo meiosis leading to the formation of polar bodies [48]. We wondered whether an analogous early activation of MAP kinase in conjunction with meiosis is detectable in the distal gonads of our parthenogenetic nematodes. Our preliminary data do not support the presence of a biphasic activation (not shown) suggesting that oocyte development as well as meiotic cell cycle regulation may be different in parthenogenetic vs. non-parthenogenetic nematodes.

In conclusion, activation of the Erk1/2 MAP kinase pathway is a hallmark of oocyte maturation in parthenogenetic nematodes as it is in many other animals. Therefore, MAP kinase activation in proximal oocytes does not mirror differences in the reproductive mode.

\section{Major sperm protein is not detectable in parthenogenetic nematodes}

MAP kinase sequences and MAP kinase activation in the germline of parthenogenetic species appear similar to the model system $C$. elegans. Consequently, we asked whether MSP, the trigger of this activation in C. elegans [28], is also present in parthenogenetic nematodes. To test this possibility, we performed immunofluorescence analysis of nematode gonads (Figure 3) with a monoclonal antibody against the highly conserved C-terminus of MSP (Figure 4D; [49]). Staining of the hermaphroditic $C$. elegans gonad gives the expected signal of sperm-associated MSP coinciding with the DAPI signal of sperm nuclei (Figure 3A, B). The same could be observed after staining the gonads of hermaphroditic and bisexual Acrobeloides species (Figure 3C, D and $3 \mathrm{E}, \mathrm{F}$ ) indicating that the C. elegans antibody is able to recognise MSP from distant groups. In the cases where we detected sperm nuclei (Figure 3B, D, F), the corresponding MSP signal appeared slightly blurred. This is consistent with the demonstration of cytoplasmatic and extracellular MSP in C. elegans [49] and suggests that the extracellular signaling function of MSP might be conserved in other nematode groups. In addition to the sperm-associated signal, the MSP antibody marked extracellular puncta at the surface of the -1 and occasionally the -2 oocyte (Figure $3 \mathrm{~A}$, inset). A similar localisation of secreted MSP in the C. elegans gonad has been reported in a previous paper [49] indicating an adequate sensitivity of our experimental setup. In contrast to the sexual species, we never observed such puncta or other MSP-related signals in gonad preparations of the parthenogenetic nematodes $A$. nanus and $D$. coronatus (Figure 3G, I). Likewise, we could not detect sperm nuclei in these species (Figure 3H, J; [48]). As sper- 
matocytes are the only known cells in nematodes where MSP is expressed [20-22,24], the absence of MSP is expected in nematodes lacking sperm.

To confirm the absence of MSP protein with an alternative method, we performed Western blot analysis of worm lysates using the C-terminal MSP antibody. In agreement with our immunostaining results, we could neither detect MSP signals in the two parthenogenetic species $A$. nanus and D. coronatus (Figure 4A) nor in two additional parthenogenetic species, Acrobeloides maximus and Zeldia punctata (Figure 4B), even if worm lysate was used in large excess (not shown). In contrast, a clear MSP signal at the size of the $C$. elegans control reveals the presence of MSP in the sperm-containing species Acrobeloides (bisex) and Acrobeloides (herma). This demonstrates cross-reactivity of the antibody to MSPs from other species as expected from the conservation of MSP C-termini in a wide range of nematodes (Figure 4D). To rule out insufficient sensitivity of our MSP detection assay, we performed a Western blot with serial dilutions of C. elegans lysate. This experiment illustrates that the antibody still detects MSP if the starting lysates are diluted hundredfold (Figure 4C).

Additional smaller bands in the Acrobeloides (bisex) lane (Figure 4A) likely represent cleavage products of MSP which have also been reported for C. elegans [49]. In some experiments, we observed an additional larger signal at $35 \mathrm{kDa}$. As MSP is known to form extremely stable dimers [50], this signal likely indicates dimerized MSP (Figure 4B, Acrobeloides (bisex) lane).

In conclusion, our results show that MSP is not detectable and thus appears to be absent at the protein level in the parthenogenetic species we analysed.

\section{Intact MSP genes are present in parthenogenetic nematodes}

Parthenogenetic nematodes do not undergo spermatogenesis during which MSP is normally expressed. Indeed, our experiments gave no evidence for its expression. We therefore expected that they do not require MSP, allowing the accumulation of mutations in MSP genes over time. A decay of genes specific to sex and recombination is predicted as an effect of the loss of sex on the eukaryotic genome [51]. To investigate this hypothesis, we cloned MSP genes from the parthenogenetic nematode $A$. nanus, from its hermaphroditic sister species Acrobeloides (herma) and from the parthenogenetic D. coronatus. We isolated and characterised several MSP genes from all three nematodes.

Figure 5A shows an alignment of representative MSP coding sequences from the two parthenogenetic nematodes and closely related hermaphroditic species. It illustrates a strong conservation of the MSP coding sequence in parthenogenetic animals (> 90\% similarity to their her- maphroditic relatives). The MSP genes from parthenogenetic species were found to be intact within the range of the primers used for amplification (AA 23-114 of 127 AA full length MSP). However, part of the C-terminus relevant for binding of the MSP antibody is missing in these sequences. Therefore, we cloned the complete 3'ends of D. coronatus and Acrobeloides (herma) MSP. As in many other MSPs (Figure 4D), this region is strictly conserved in D. coronatus and Acrobeloides (herma) (Figure 5A), excluding the possibility that parthenogenetic species possess a modification within this epitope that prevents detection.

Besides intact genes with no signs of degeneration we also detected an exception in A. nanus where several stops in the coding region indicate a pseudogene (not shown). Pseudogenes containing frameshifts or short deletions were also present in some MSP clones from Acrobeloides (herma) (not shown), in agreement with a number of pseudogenes in the large $C$. elegans MSP gene family $[52,53]$.

MSP sequences obtained from several nematode species contain introns [23,54-57]. In agreement with these reports, we predict the presence of introns in the parthenogenetic MSP sequences we cloned (Figure 5A). While intron phase is variable in previously published MSP sequences and our own, intron position and number is conserved. All introns follow the GT-AG rule [58]. In most species, including the parthenogenetic $A$. nanus and $D$. coronatus, a single intron of $60-70 \mathrm{bp}$ is situated at amino acid position 33 [54-56]. D. coronatus is the only nematode so far where a second MSP intron is present (194 bp, after AA 83; Figure 5A). A strict conservation of intron position like in the nematode MSPs is observed in a substantial fraction of eukaryotic genes over distant taxa and may reflect an evolutionary conservation of ancient introns [59].

Our finding of apparently intact MSP genes in D. coronatus and $A$. nanus is based on fragments that lack the $5^{\prime}$ and/or the 3' end of the coding regions. Therefore, we cannot exclude that mutations are present in the missing parts (22 AA and $12 \mathrm{AA}$, respectively). As whole genome sequences do not exist for either nematode, we looked for MSP coding regions in parthenogenetic species with a sequenced genome [60,61]. Via BLAST searches, we identified among partial sequences and pseudogenes a set of complete MSP coding sequences in the genomes of the obligately parthenogenetic [62] nematode Meloidogyne incognita and its facultatively parthenogenetic [63] sister species Meloidogyne hapla. We compared this MSP set to our above obtained sequences and to published MSP sequences from other, non-parthenogenetic nematodes. The deduced protein sequences of $M$. incognita and $M$. hapla are almost identical with each other (> 98\%; Figure 5B). They have $73 \%$ and $67 \%$ identity to MSP sequences 

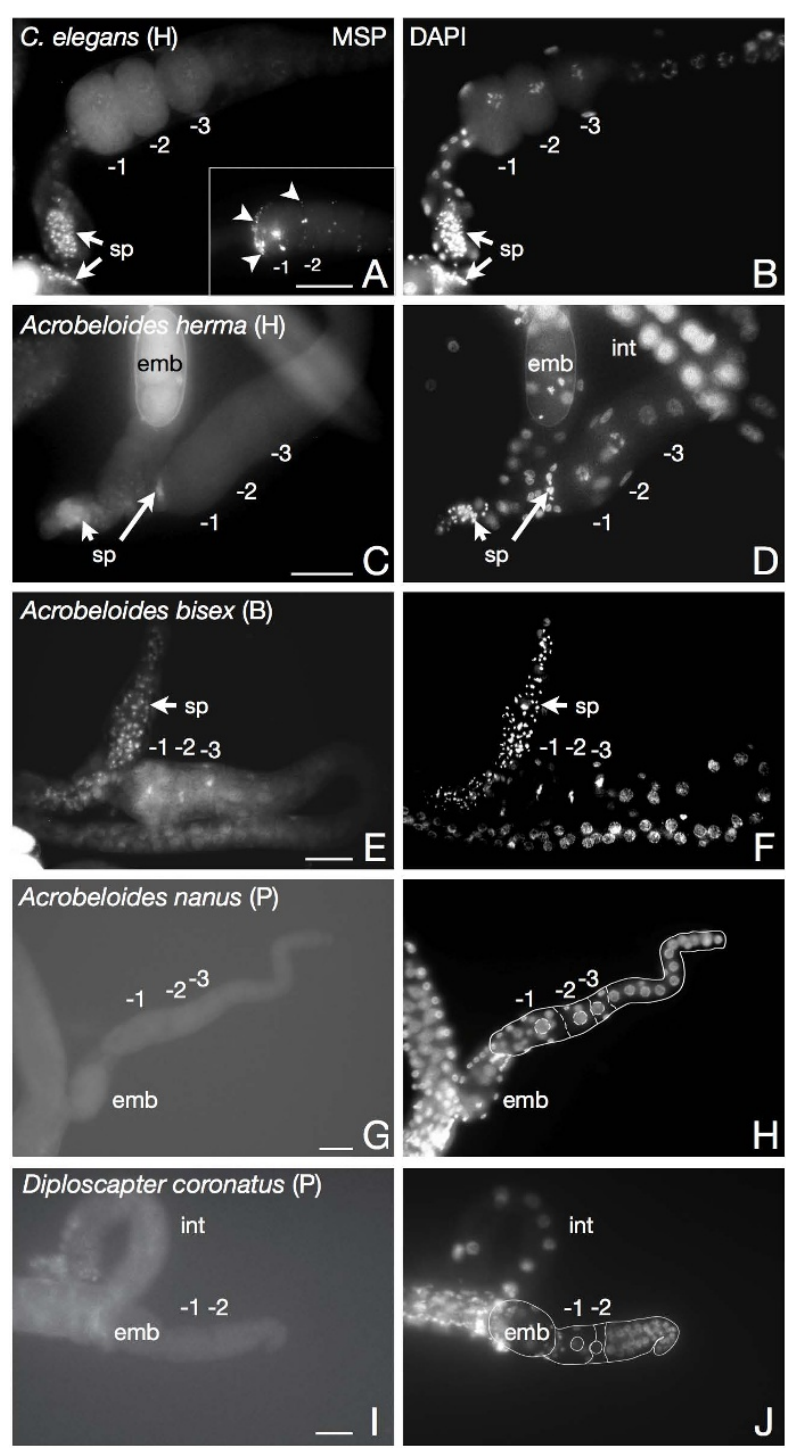

Figure 3 Immunofluorescence analysis of MSP in nematode gonads. Dissected gonad preparations of parthenogenetic $(P)$, hermaphro $\operatorname{ditic}(\mathrm{H})$ and bisexual (B) nematodes were doubly stained for MSP (left panel) and DNA (DAPI, right panel). While sperm associated MSP is revealed in the hermaphrodites C. elegans (panel A) and the distantly related species Acrobeloides (herma) and Acrobeloides (bisex) (panels C, E; arrows), a signal cannot be spotted in the parthenogenetic species $A$. nanus and $D$. coronatus (panels $G, I$ ). Arrowheads in panel $A$, inset, indicate puncta at the surface of the -1 oocyte resembling extracellular MSP as published previously [49]. The inset of panel A and panels $G-J$ are from the same experiment, panels A-F from another. The photographs of parthenogenetic animals were overexposed to demonstrate the lack of staining, and their gonadal shape is outlined for better orientation. sp: sperm. st: spermatheca. int: intestine. emb: embryo. -1, -2, -3: proximal oocytes, -1 is most proximal. All gonads are oriented with proximal to the left. Bar: $20 \mu \mathrm{m}$

from C. elegans or A. nanus, respectively. Intron position (lysine 33) and number (one intron) are identical in all Meloidogyne MSPs investigated here and agree with our data from the parthenogenetic nematodes $A$. nanus and $D$. coronatus as well as with results from other species [54-56]. Intron length is very similar in all Meloidogyne MSPs (60-70 bp) and comparable to MSP sequences from other nematodes (data not shown; [55,57]). In support of our findings, a former study reported the absence of an increased evolutionary rate and of a change in the substitution pattern in MSP sequences from parthenogenetic Meloidogyne species [64].

To assess the translation potential of Meloidogyne MSPs, we investigated the regions flanking the AUG initiator codon. According to Kozak's rules, a consensus sequence surrounding the AUG codon is critical for a favourable context of translation initiation [65-67]. In all Meloidogyne MSP loci analysed, we find purines (A) at the -3 position and the nucleotide $G$ in position +4 (not shown) as it was previously reported for MSP transcripts isolated from G. rostochiensis and D. viviparus [23,55]. This indicates that the respective MSP start codons fulfill the requirements for a successful initiation of translation regardless of the reproductive mode.

Thus, a remarkable conservation in genomic organisation and deduced protein sequence exists in MSPs from several parthenogenetic nematodes positioned in different clades.

\section{Discussion}

MAP kinase activation via a hormone-dependent pathway is an essential step during oocyte-to-embryo transition of all animals. In the model organism C. elegans, the hormonal trigger for oocyte maturation and MAP kinase activation is MSP, a cytoskeletal protein secreted from sperm [28]. In addition, recent evidence suggests that MSP action on somatic gonadal sheath cells regulates the production, growth and meiotic maturation of oocytes $[31,68]$. Oocyte meiotic progression and ovulation therefore strictly depend on the presence of sperm in C. elegans. As different modes of reproduction exist in the phylum Nematoda, including many examples of parthenogenesis (for review see $[32,33]$ ), we investigated two key elements of meiotic progression, MAP kinase activation and the expression of MSP, in parthenogenetic nematode species that lack sperm.

\section{MAP kinase activation as a common theme in oocyte maturation}

We have cloned MAP kinase genes from parthenogenetic nematodes. Phylogenetic analysis confirmed that they belong to the Erk1/2 subfamily of MAP kinases involved in oocyte maturation in many animals (Figure 1B). If MAP kinases of parthenogenetic nematodes had specific alterations, we would expect them to form a cluster separate from the MAP kinases of hermaphroditic species. Our analysis revealed, however, that this is not the case. 


\section{A}
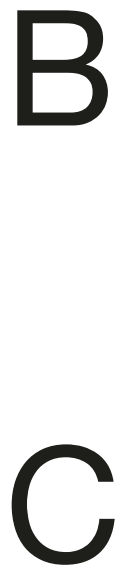

D

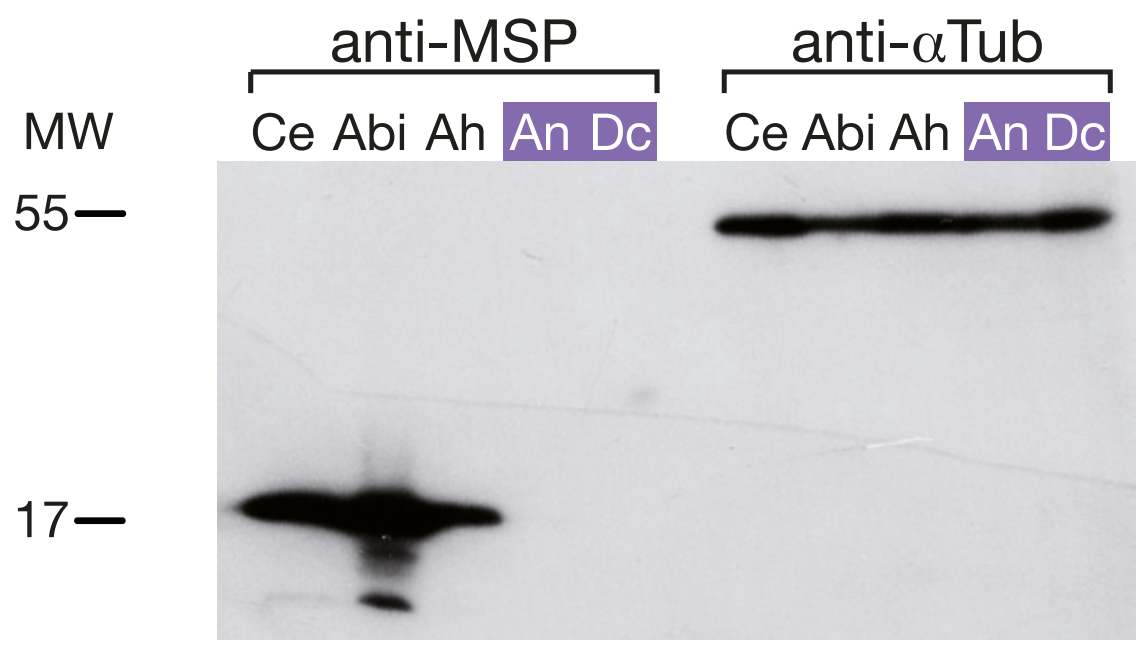

Ce Abi An Ax Zp Ce Abi An Ax Zp

$55-$

$36-$

$17-$
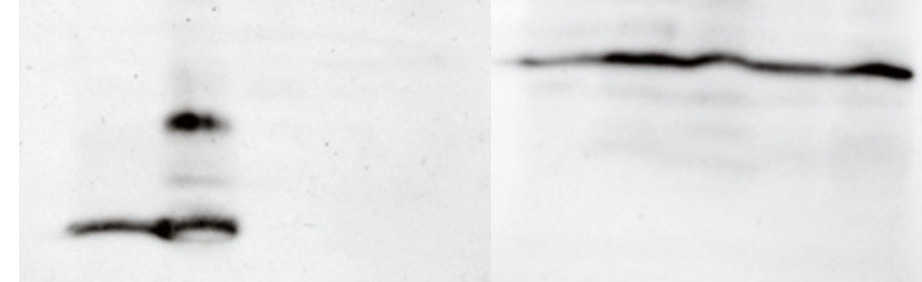

17 -

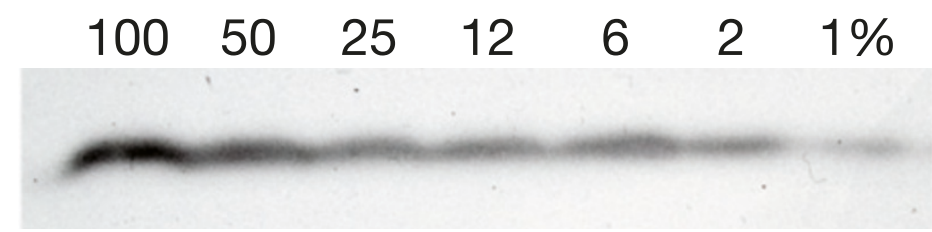

$\begin{array}{lll} & 100 & 110 \\ \text { CeMsp-19 } & \text { GAAKQFRREWFQGDGMVRRKNLPIEYNP } \\ \text { OvMsp-1 } & \text { GAAKQFRREWFQGDGMVRRKNLPIEYNL } \\ \text { AsMsp- } 3 & \text { GAAKQFRREWFQGDGMVRRKNLPIEYNL } \\ \text { GrMsp-1 } & \text { PAAAAFKLEWFQGDGMVRRKNLPIEYNV }\end{array}$

MSP C-terminal epitope

Figure 4 MSP analysis in whole nematode extracts. A: MSP is not detectable by Western blot in lysates of the parthenogenetic nematodes A. nanus and D. coronatus. Lysates of nematodes with various reproductive modes were, in roughly equal amounts, subjected to SDS-PAGE and Western blotting. One membrane of a duplicate set was incubated with monoclonal anti-MSP antibody, the other as a control with anti- $\alpha$-tubulin antibody. While MSP is recognised in C. elegans and hermaphroditic or bisexual representatives of the distant Acrobeloides genus, none of the parthenogenetic species (violet) displays a signal. Ce: C. elegans; Abi: Acrobeloides (bisex); Ah: Acrobeloides (herma); An: A. nanus; Dc: D. coronatus. MW: molecular weight [kDa]. B: MSP is not detectable in additional parthenogenetic nematode species. As above, roughly equal amounts of nematode lysate were subjected to SDS-PAGE and Western blotting. While MSP is recognised in C. elegans and the sperm producing Acrobeloides (bisex), two further parthenogenetic species (violet) do not reveal a signal. Ce: C. elegans; Abi: Acrobeloides (bisex); An: A. nanus; Ax: A. maximus; Zp: Z. punctata. MW: molecular weight [kDa]. C: MSP is detectable over a wide range of concentrations. Serial dilutions of C. elegans lysates were subjected to SDS-PAGE and Western blotting using the monoclonal anti-MSP antibody. Numbers above the lanes indicate the relative amount of lysate used. 100\% approximately correspond to $8 \mathrm{mg}$ of worms, the amount used in experiments 4A and 4B. D: The C-terminal epitope recognised by the MSP antibody is widely conserved throughout the Nematode phylum. An alignment of C. elegans and other MSP sequences, derived from nematodes of clades 8-12 (Figure 1A), demonstrates the almost perfect conservation of MSP C-termini in a wide phylogenetic range. Accession numbers: Ce (C. elegans, AAC26926.1); Ov (Onchocerca volvulus, J04662.1); As (Ascaris suum, P27440.3); Gr (Globodera rostochiensis, AAA29146.1). 


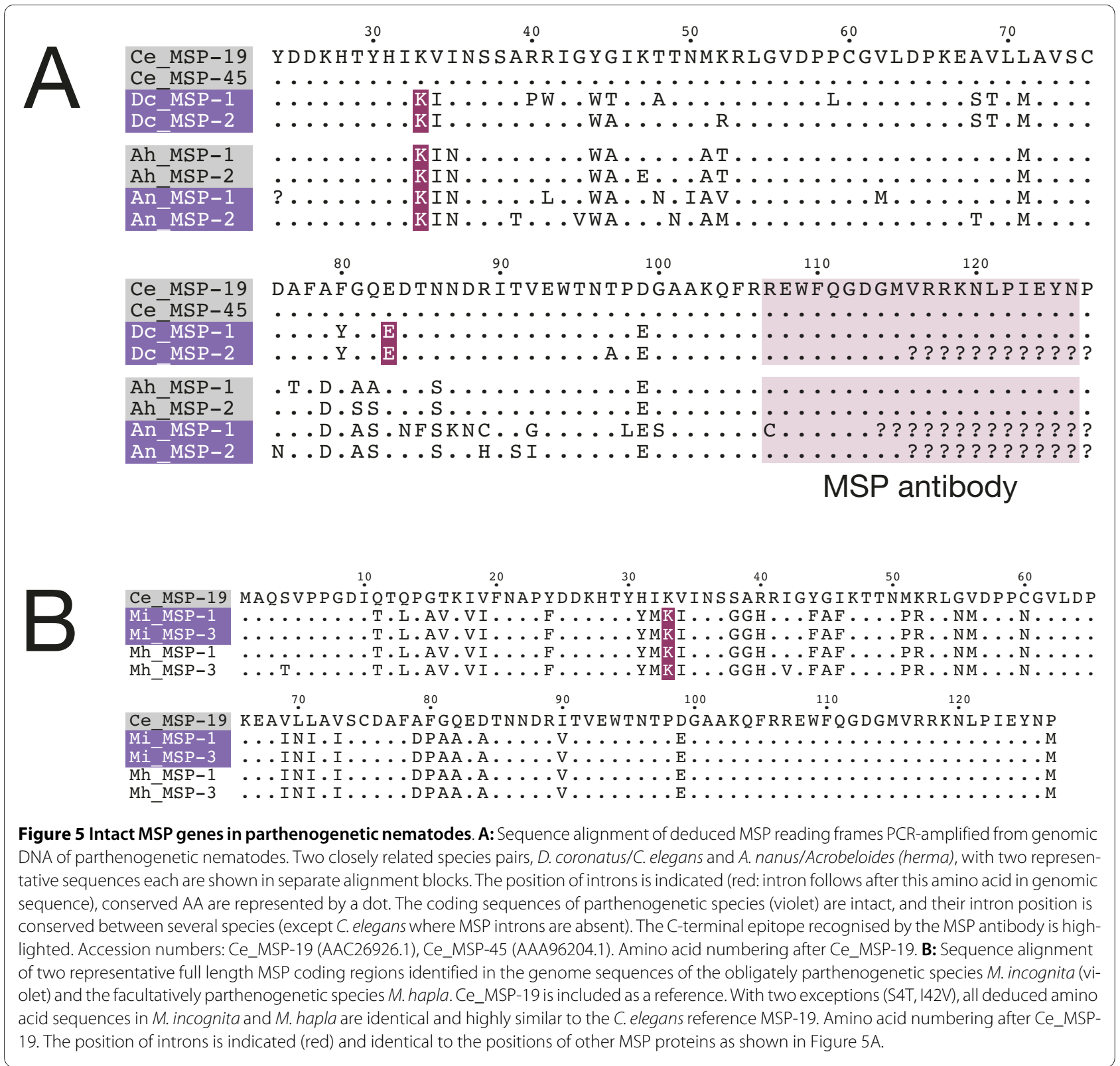

The tree based on MAP kinase sequences reflects the accepted phylogenetic relationships (Figure 1B). Moreover, an 11 AA epitope which is recognised by the MAP kinase antibody is identical in Erk1/2 of humans, C. elegans and parthenogenetic nematodes (Figure $1 C$ ). Therefore, the MAP kinase activation we detect in parthenogenetic worms (Figure 2) is specific for Erk1/2 and corresponds to the oocyte-to-embryo transition in $C$. elegans and other animals.

Although a direct involvement of MAP kinase activation in oocyte maturation is demonstrated in C. elegans [34] and other systems [69,70], our data do not prove a similar role in parthenogenetic nematodes. However, considering the widespread utilisation of MAP kinase sig- naling for this developmental step, an alternative mechanism for meiotic maturation and cell cycle progression and hence activation of MAP kinase independently of meiotic maturation seems unlikely. Functional studies could show whether MAP kinase activation is directly required for oocyte-to-embryo transition in parthenogenetic species. Methodological limitations, however, prevent a reliable RNAi-mediated knockdown in these nematodes at the present time ( $\mathrm{PH}$, unpublished data). Thus, based on the presence of Erk1/2 MAP kinase activation in parthenogenetic nematodes at the time of oocyte maturation, we argue that this critical step is conserved independent of the reproductive mode. 


\section{An elusive role for MSP in parthenogenetic nematodes}

Detection of MAP kinase activity in maturing oocytes of parthenogenetic nematodes let us explore the role of MSP as a potential trigger for this activation. Using an antibody directed against the C-terminus of $C$. elegans MSP [49], we analysed MSP expression in parthenogenetic nematodes by two independent methods, immunofluorescence and Western blotting. The well-known identity of MSP C-termini in a wide range of nematodes, at least from Ascaris to Caenorhabditis (Figure 4D; [28]), already suggests a cross-reactivity of the antibody with MSPs from the Acrobeloides and Diploscapter group. Indeed, both methods were able to detect heterologous MSP of the non-parthenogenetic nematodes Acrobeloides (herma) and Acrobeloides (bisex) which are closely related to the parthenogenetic A. nanus (Figure 3C, E; 4A, B). Moreover, our experimental setup was sensitive enough to detect small puncta of extracellular MSP in the gonads of C. elegans (Figure 3A, inset) as reported in a previous paper [49]. Despite these controls, we were not able to identify even weak MSP signals in the parthenogenetic species $D$. coronatus and $A$. nanus (Figure 3G, I; Figure $4 \mathrm{~A}, \mathrm{~B})$. To rule out possible alterations of the antibody recognition site in parthenogenetic nematodes, we cloned MSP C-termini from the parthenogenetic D. coronatus and from Acrobeloides (herma). We chose Acrobeloides (herma), the hermaphroditic sister species to $A$. nanus, because cloning of $A$. nanus MSP was not successful. The C-terminal MSP sequences we isolated were identical to the respective $C$. elegans epitope at the amino acid level (Figure 5A), making antibody failure an unlikely explanation for the absence of a signal. Therefore, our observations are consistent with the absence of MSP at the protein level in the parthenogenetic species and with the fact that MSPs are expressed exclusively in developing spermatocytes or males in C. elegans and other nematodes [19-24].

In contrast to our findings, a previous paper reported the presence of MSP in two parthenogenetic species of the cephalobid group (clade 11), Acrobeloides maximus and Zeldia punctata [49]. However, evidence for MSP expression delivered in this paper is uncertain as no appropriate controls are presented. First, immunostaining of the A. maximus gonad detected puncta that could represent secreted MSP. However, they could also be an artefact, the more as the signal is positioned in the distal gonad where it is absent in C. elegans [49]. Close inspection of the data further indicates a high amount of puncta filling the entire space between oocyte nuclei. This observation would imply abundant expression of MSP in $A$. maximus and other parthenogenetic nematodes which is not the case according to our data (Figure 4).

Second, a Western blot suggests expression of MSP in the parthenogenetic species $A$. maximus and $Z$. punctata.
Although we have used a different batch of the same antibody, our inability to reproduce this result can not be caused by a lower sensitivity. Expression levels of MSP in the parthenogenetic species as presented by [49] are twoto threefold weaker than in C. elegans and still suggest abundant expression. Using serial dilutions we showed that it is possible for us to detect at least 1\% of MSP input (Figure 4C). This dynamic range demonstrates that our assay is definitely sensitive enough to detect the somewhat lower MSP expression in parthenogenetic nematodes shown by [49]. A possible reason for these discrepancies could be species-specific differences in MSP expression as we investigated different parthenogenetic Acrobeloides species (A. nanus vs. A. maximus). To test this assumption, we analysed cell extracts from $A$. maximus and Z. punctata, but MSP was undetectable in these nematodes either (Figure 4B). Thus, we were unable to reproduce MSP expression in four different parthenogenetic species.

Despite their absence as protein, we showed for the first time that intact MSP genes with features of active genes are present in parthenogenetic nematodes from several clades. Three factors may contribute - possibly in combination - to the maintenance of MSP genes in parthenogenetic nematodes:

(i) Although we could never find males in A. nanus and D. coronatus, anecdotal evidence suggests their appearance in some parthenogenetic cultures from time to time (e. g. in A. maximus or Plectus mekong; P. De Ley, personal communication; ES, unpublished; [32]). The high percentage of male progeny observed in such cultures suggests that they are able to reproduce, requiring functional sperm. Thus, MSP genes may be retained to permit occasional emergence of males in parthenogenetic species. Support for this view comes from the parthenogenetic nematode Aphelenchus avenae where production of numerous males upon heat or chemical treatment has been described [71,72]. Males have also been observed in the root knot nematode $M$. incognita $[73,74]$ which is considered to be obligately parthenogenetic [62]. Although it is not known whether these examples are exceptions or the rule, they illustrate a high degree of intraspecific variation and a lack of understanding the underlying mechanisms. Obviously, a strategy of mixing parthenogenesis with sexual reproduction instead of pursuing parthenogenesis alone can be evolutionarily beneficial.

(ii) The preservation of MSP genes in parthenogenetic nematodes may be explained by a recent transition to parthenogenesis. Evolution did not yet modify MSP genes, and although they are obsolete, we find them still intact. A model where parthenogenesis constantly emerges and disappears in different branches of nematodes could account for these observations. A feature of 
this model, supported by theoretical considerations [75,76], is that parthenogenesis is disadvantageous and destined for extinction on the long run. Following this idea, parthenogenesis can be observed in different branches of the nematode tree at a given time, but it is always of recent origin because disadvantages prevent its long-term preservation.

Although this is an attractive hypothesis, presently no data exist for its direct proof which would e. g. require the inactivation of intact MSPs in a parthenogenetic background. Nevertheless, a detailed comparison of MSP sequences in non-parthenogenetic vs. parthenogenetic root knot nematodes proposed a recent origin of parthenogenesis based on the absence of an increased substitution rate, changed substitution pattern or pseudogene formation [64]. These results, however, could also be explained assuming a strong selective pressure on the maintenance of MSP genes, as in scenario (i) and (iii).

(iii) As a third possibility, MSP genes might be conserved because MSP is needed to trigger oocyte maturation in parthenogenetic species like in C. elegans. Albeit this view is not supported by our data, we cannot exclude the presence of MSP at levels too low for detection via Western blotting and immunofluorescence. MSP is deprived of structural and motility functions in spermless parthenogenotes. Thus, a low expression level could be sufficient for acting like a hormone in MAP kinase signaling and oocyte maturation. This model would implicate a shift in MSP expression from sperm to non-sperm cells which could be achieved by mutations in regulatory sites. As C. elegans MSP is exported from sperm by a non-classical vesicle budding mechanism [49], one would further expect a similar mechanism in oocytes or sheath cells of parthenogenetic nematodes which is not known at the present time. Despite the absence of direct experimental support, this last interpretation would require only minimal changes in the initial hermaphroditic system. Existing signaling pathways could be used to control oocyte maturation after transition to parthenogenesis.

With the presently available data it is not possible to distinguish between the presented alternatives. Unlike the first two scenarios, the last hypothesis provides a number of reasonable predictions and may serve as a starting point for further analysis.

\section{Conclusions}

The C. elegans oocyte-to-embryo transition is governed by MSP, a cytoskeletal protein released from sperm, and is therefore coupled to the presence of sperm. Within the Nematoda, reproduction is highly versatile, and parthenogenesis, reproduction without the contribution of sperm, has evolved many times independently. To elucidate oocyte-to-embryo transition in nematodes that lack sperm, we have investigated two of its hallmarks, MAP kinase activation and MSP signaling, in two representative parthenogenetic species. Activation of MAP kinase in parthenogenetic nematodes at the time of oocyte maturation implies that this signal does not constitute a simple switch whose presence or absence determines the reproductive mode. Instead, it might regulate meiotic cell cycle progression of maturing oocytes independent of the reproductive mode.

MSP, the major sperm protein, has no apparent function in parthenogenetic nematodes that lack sperm. Indeed, we demonstrate its absence at the protein level. However, the unexpected discovery of intact MSP genes suggests either their strong maintenance by natural selection or a very recent origin of parthenogenesis in the nematode branches we examined.

\section{Methods}

\section{Nematode cultivation and strains}

All nematodes were cultivated under standard conditions [77], feeding on agar plates with E. coli OP50 as a food source. To reduce contamination with other bacteria, we used minimal medium plates [78]. Studies were carried out with the following strains: C. elegans N2 (hermaphroditic [77]), Acrobeloides sp. PS1146 (hermaphroditic; kindly provided by Marie-Anne Felix, France; for simplicity called Acrobeloides (herma)), Acrobeloides sp. 0/5061 (gonochoristic; kindly provided by Walter Sudhaus, Berlin, Germany; for simplicity called Acrobeloides (bisex)), Acrobeloides nanus ES501 (parthenogenetic [79]; called A. nanus), Diploscapter coronatus PDL0010 (parthenogenetic; kindly provided by Paul De Ley, University of California, Riverside; called $D$. coronatus).

\section{Immunostaining and Western blot}

For visualisation of MAP kinase and MSP, we prepared and immunostained nematode gonads as described $[28,80]$. Briefly, $\geq 50$ nematodes were dissected in $1 \times$ Egg Salts containing $0.01 \%$ Levamisole (Sigma). After fixation in 3\% Formaldehyde (Science Services) for $1 \mathrm{~h}$, specimens were washed (PBST) and incubated either with a monoclonal antibody against MAP kinase (1:1.500) that only recognises the activated, diphosphorylated form of the Erk1/2 activation loop (Sigma \# M9692) or with a monoclonal antibody (1:400) raised against the C-terminus of C. elegans MSP [49]. Secondary antibody was an Alexa Fluor 488 coupled goat anti-mouse antibody at a 1:1.000 dilution (Invitrogen). Microscopy was carried out with a Zeiss Axioskop 2 fluorescence microscope. Pictures were taken with an AxioCam MRc camera (Zeiss) and arranged with the Keynote software (Apple).

For detection of MSP in nematode lysates, $40 \mathrm{mg}$ animals (mixed stage population) of the respective species were washed in $\mathrm{H}_{2} \mathrm{O}$, freeze-cracked twice in liquid nitrogen/ice, and boiled for $10 \mathrm{~min}$ in SDS loading buffer. 
After electrophoresis on a $12 \%$ SDS gel, proteins were electroblotted onto PVDF membranes under semidry conditions and subjected to Western detection. Primary antibody was the monoclonal anti-MSP antibody directed against the C-terminus of MSP [49] at 1:400 or, as a control, a 1:3.000 dilution of a mouse monoclonal anti- $\alpha$-tubulin antibody (Sigma \# T9026). Secondary antibody was a HRP-coupled goat anti-mouse antibody at 1:2.500 (Santa Cruz Biotechnology, Inc.). Antibodies were diluted in TBST $/ 2 \%$ milk powder. Autoradiographic films (Fuji) were developed according to standard protocols, digitally scanned and processed with Keynote.

\section{Cloning of MAP kinase and MSP genes}

To clone MAP kinase sequences, RNA was extracted from various nematodes and cDNA was synthesised as described earlier [81]. Initially, the conserved kinase regions of MAP kinase were PCR amplified from cDNA using degenerate primers. The corresponding 5 'ends were obtained via PCR with a gene specific reverse primer and the conserved SL1 splice leader [82] as forward primer. The 3 'ends were fished with a gene specific forward primer and the reverse primer mixture of the Smart RACE protocol (Clontech Laboratories, Inc.). For cloning of the MSP reading frames, genomic DNA of the respective nematodes was extracted with standard methods [83]. A combined degenerate and inverse PCR approach was employed to obtain genomic MSP fragments that included the 3 'end. Amplification products were cloned into the pJet1 vector (Fermentas), transformed into E. coli XL1-Blue bacteria (Stratagene) and sequenced with the BigDye Terminator V3.1 sequencing kit (Applied Biosystems). Sequence assembly and editing were carried out using the Phred/Phrap/Consed package $[84,85]$ and the plasmid editor ApE http://www.biology.utah.edu/jorgensen/wayned/ape/. The mentioned MAP kinase and MSP sequences were deposited at the EMBL Nucleotide Sequence Database (accession numbers: FN667822-FN667824 for MAP kinase, FN433114FN433119 for MSP sequences).

\section{Detection of MSP genes in Meloidogyne}

Whole genome sequences from $M$. incognita and $M$. hapla $[60,61]$ were downloaded from NCBI and translated to the six open reading frames using Emboss [86]. After constructing BLAST databases [87], BLASTP searches identified MSP coding contigs within the respective genomes. Based on this information, MSP genes were annotated using Artemis [88] and the resulting sequences were deposited at the EMBL Nucleotide Sequence Database (accession numbers: FN433120FN433123). Methods for sequence alignment and presentation see below.

\section{Sequence alignment and phylogenetic analysis}

For alignment and phylogeny of MAP kinase proteins, following MAP kinase sequences were retrieved from NCBI http://www.ncbi.nlm.nih.gov/protein: C. elegans MPK-1 and MPK-2 (Accession numbers P39745.2 and AAN60533.1), human and zebrafish Erk1 (P27361.4 and AAY57804.1), human Erk2 (NP_620407.1), human and zebrafish Erk5 (Q13164.2 and ABC94477.1), human, zebrafish and C. elegans p38 (Q16539.3, NP_571797.1 and AAM98016.1), human and zebrafish Jnk (NP_620707.1 and NP_571796.1), zebrafish Erk3 (ABC94479.1) and human Erk4 (NP_002738.2). A protein multiple sequence alignment was computed from the retrieved and our isolated MAP kinase sequences using Muscle [89]. The alignment was trimmed to the well alignable region of roughly the serine-threonine kinase domain (317 amino acid positions) in SeaView [90]. Details of aligned regions were produced using TEXshade [91]. Phylogenetic trees of the MAP kinase dataset were computed using the maximum likelihood method. First, the optimal model of sequence evolution was determined by ProtTest version 2.0 [92] according to the Akaike Information Criterion. The resulting optimal model (RtREV) was used for maximum likelihood with the program PhyML version 3.0 and 100 bootstrap replicates [93]. The initial tree was visualised with Phylip [94] and edited with Adobe Illustrator software.

\section{Authors' contributions}

PH performed most experiments and wrote the paper. MK and NN cloned the MAP kinase genes. NN and PH cloned the MSP genes. MK, ES, and PH designed the study and discussed the results. ES critically revised the manuscript. All authors read and approved the final manuscript.

\section{Acknowledgements}

Thanks to Hayati Özden for first-class technical assistance. The Bioinformaticians and Linux community for excellent open source software. Eva Heger for helpful discussion. The monoclonal MSP C-terminal antibody developed by David Greenstein was obtained from the Developmental Studies Hybridoma Bank maintained by The University of lowa, Department of Biology, lowa City, IA 52242. This research was supported by grants from the Deutsche Forschungsgemeinschaft to ES (SFB 680).

Author Details

Zoological Institute, University of Cologne, Zülpicher Strasse 47b, 50674 Köln, Germany

Received: 14 September 2009 Accepted: 17 May 2010 Published: 17 May 2010

\section{References}

1. Sagata N: What does Mos do in oocytes and somatic cells? Bioessays 1997, 19:13-21.

2. Nebreda AR, Ferby I: Regulation of the meiotic cell cycle in oocytes. Curr Opin Cell Biol 2000, 12(6):666-75.

3. Abrieu A, Doree M, Fisher D: The interplay between cyclin-B-Cdc2 kinase (MPF) and MAP kinase during maturation of oocytes. J Cell Sci 2001, 114(Pt 2):257-67.

4. Waskiewicz AJ, Cooper JA: Mitogen and stress response pathways: MAP kinase cascades and phosphatase regulation in mammals and yeast. Curr Opin Cell Biol 1995, 7(6):798-805. 
5. Widmann C, Gibson S, Jarpe MB, Johnson GL: Mitogen-activated protein kinase: conservation of a three-kinase module from yeast to human. Physiol Rev 1999, 79:143-80.

6. Rossomando AJ, Payne DM, Weber MJ, Sturgill TW: Evidence that pp42, a major tyrosine kinase target protein, is a mitogen-activated serine/ threonine protein kinase. Proc Natl Acad Sci USA 1989, 86(18):6940-3.

7. Cobb MH, Goldsmith EJ: How MAP kinases are regulated. J Biol Chem 1995, 270(25):14843-6.

8. Chen RH, Sarnecki C, Blenis J: Nuclear localization and regulation of erkand rsk-encoded protein kinases. Mol Cell Biol 1992, 12(3):915-27.

9. Gonzalez FA, Seth A, Raden DL, Bowman DS, Fay FS, Davis RJ: Seruminduced translocation of mitogen-activated protein kinase to the cell surface ruffling membrane and the nucleus. J Cell Biol 1993, 122(5):1089-101.

10. Sun $\mathrm{H}$, Charles $\mathrm{CH}$, Lau LF, Tonks NK: MKP-1 (3CH134), an immediate early gene product, is a dual specificity phosphatase that dephosphorylates MAP kinase in vivo. Cell 1993, 75(3):487-93.

11. Lackner MR, Kornfeld K, Miller LM, Horvitz HR, Kim SK: A MAP kinase homolog, mpk-1, is involved in ras-mediated induction of vulval cell fates in Caenorhabditis elegans. Genes Dev 1994, 8(2):160-73.

12. Wu Y, Han M: Suppression of activated Let-60 ras protein defines a role of Caenorhabditis elegans Sur-1 MAP kinase in vulval differentiation. Genes Dev 1994, 8(2):147-59.

13. Moghal N, Sternberg PW: The epidermal growth factor system in Caenorhabditis elegans. Exp Cell Res 2003, 284:150-9.

14. Sundaram MV: RTK/Ras/MAPK signaling. WormBook 2006:1-19.

15. Smith H: Sperm motility and MSP. WormBook 2006:1-8.

16. Klass MR, Hirsh D: Sperm Isolation and Biochemical Analysis of the Major Sperm Protein from Caenorhabditis elegans. Dev Biol 1981, 84:299-312

17. Burke DJ, Ward S: Identification of a large multigene family encoding the major sperm protein of Caenorhabditis elegans. J Mol Biol 1983, 171:1-29.

18. Scott AL, Dinman J, Sussman DJ, Ward S: Major sperm protein and actin genes in free-living and parasitic nematodes. Parasitology 1989, 98(Pt 3):471-8.

19. Cottee PA, Nisbet AJ, Boag PR, Larsen M, Gasser RB: Characterization of major sperm protein genes and their expression in Oesophagostomum dentatum (Nematoda: Strongylida). Parasitology 2004, 129(Pt 4):479-90.

20. Ward S, Klass M: The location of the major protein in Caenorhabditis elegans sperm and spermatocytes. Dev Biol 1982, 92:203-8.

21. Klass M, Dow B, Herndon M: Cell-specific transcriptional regulation of the major sperm protein in Caenorhabditis elegans. Dev Biol 1982, 93:152-64.

22. Jiang D, Li BW, Fischer PU, Weil GJ: Localization of gender-regulated gene expression in the filarial nematode Brugia malayi. Int J Parasitol 2008, 38(5):503-12.

23. Strube C, Buschbaum S, Schnieder T: Molecular characterization and real-time PCR transcriptional analysis of Dictyocaulus viviparus major sperm proteins. Parasitol Res 2009, 104(3):543-51.

24. Bennett KL, Ward S: Neither a germ line-specific nor several somatically expressed genes are lost or rearranged during embryonic chromatin diminution in the nematode Ascaris lumbricoides var. suum. Dev Biol 1986, 118:141-7.

25. Sepsenwol S, Ris H, Roberts TM: A unique cytoskeleton associated with crawling in the amoeboid sperm of the nematode, Ascaris suum. J Cell Biol 1989, 108:55-66.

26. Nelson GA, Roberts TM, Ward S: Caenorhabditis elegans spermatozoan locomotion: amoeboid movement with almost no actin. J Cell Biol 1982, 92:121-31.

27. King KL, Stewart M, Roberts TM, Seavy M: Structure and macromolecular assembly of two isoforms of the major sperm protein (MSP) from the amoeboid sperm of the nematode, Ascaris suum. J Cell Sci 1992, 101 (Pt 4):847-57.

28. Miller MA, Nguyen VQ, Lee MH, Kosinski M, Schedl T, Caprioli RM, Greenstein D: A sperm cytoskeletal protein that signals oocyte meiotic maturation and ovulation. Science 2001, 291(5511):2144-7.

29. Miller MA, Ruest PJ, Kosinski M, Hanks SK, Greenstein D: An Eph receptor sperm-sensing control mechanism for oocyte meiotic maturation in Caenorhabditis elegans. Genes Dev 2003, 17(2):187-200.
30. Govindan JA, Cheng H, Harris JE, Greenstein D: Galphao/i and Galphas signaling function in parallel with the MSP/Eph receptor to control meiotic diapause in C. elegans. Curr Biol 2006, 16(13):1257-68

31. Govindan JA, Nadarajan S, Kim S, Starich TA, Greenstein D: Somatic cAMP signaling regulates MSP-dependent oocyte growth and meiotic maturation in C. elegans. Development 2009, 136(13):2211-21.

32. Maupas E: Modes et formes de reproduction des nematodes. Archives de Zoologie Experimentale et Generale 1900, 8:463-624.

33. Triantaphyllou AC, Hirschmann H: Reproduction in plant and soil nematodes. Annu Rev Phytopathol 1964, 2:57-80.

34. Lee MH, Ohmachi M, Arur S, Nayak S, Francis R, Church D, Lambie E, Schedl T: Multiple functions and dynamic activation of MPK- 1 extracellular signal-regulated kinase signaling in Caenorhabditis elegans germline development. Genetics 2007, 177(4):2039-62.

35. Holterman $\mathrm{M}$, Wurff A van der, Elsen $\mathrm{S}$ van den, van Megen $\mathrm{H}$, Bongers $\mathrm{T}$, Holovachov O, Bakker J, Helder J: Phylum-wide analysis of SSU rDNA reveals deep phylogenetic relationships among nematodes and accelerated evolution toward crown Clades. Mol Biol Evol 2006, 23(9):1792-800

36. Cooper JA: Related proteins are phosphorylated at tyrosine in response to mitogenic stimuli and at meiosis. Mol Cell Biol 1989, 9(7):3143-7.

37. Sanghera JS, Paddon HB, Bader SA, Pelech SL: Purification and characterization of a maturation-activated myelin basic protein kinase from sea star oocytes. J Biol Chem 1990, 265:52-7.

38. Posada J, Sanghera J, Pelech S, Aebersold R, Cooper JA: Tyrosine phosphorylation and activation of homologous protein kinases during oocyte maturation and mitogenic activation of fibroblasts. Mol Cell Biol 1991, 11(5):2517-28

39. Gotoh Y, Nishida E, Matsuda S, Shiina N, Kosako H, Shiokawa K, Akiyama T, Ohta K, Sakai H: In vitro effects on microtubule dynamics of purified Xenopus M phase-activated MAP kinase. Nature 1991, 349(6306):251-4.

40. Sobajima T, Aoki F, Kohmoto K: Activation of mitogen-activated protein kinase during meiotic maturation in mouse oocytes. J Reprod Fertil 1993, 97(2):389-94.

41. Bieri T, Blasiar D, Ozersky P, Antoshechkin I, Bastiani C, Canaran P, Chan J, Chen N, Chen WJ, Davis P, Fiedler TJ, Girard L, Han M, Harris TW, Kishore R, Lee R, McKay S, Muller HM, Nakamura C, Petcherski A, Rangarajan A, Rogers A, Schindelman G, Schwarz EM, Spooner W, Tuli MA, Van Auken K, Wang D, Wang X, Williams G, Durbin R, Stein LD, Sternberg PW, Spieth J: WormBase: new content and better access. Nucleic Acids Res 2007:D506-10

42. Abe J, Kusuhara M, Ulevitch RJ, Berk BC, Lee JD: Big mitogen-activated protein kinase 1 (BMK1) is a redox-sensitive kinase. J Biol Chem 1996, 271(28):16586-90

43. McCarter J, Bartlett B, Dang T, Schedl T: On the control of oocyte meiotic maturation and ovulation in Caenorhabditis elegans. Dev Biol 1999 205:111-28.

44. Wiegner $\mathrm{O}$, Schierenberg $\mathrm{E}$ : Specification of gut cell fate differs significantly between the nematodes Acrobeloides nanus and Caenorhabditis elegans. Dev Biol 1998, 204:3-14.

45. Edgar LG, Wolf N, Wood WB: Early transcription in Caenorhabditis elegans embryos. Development 1994, 120(2):443-51.

46. Church DL, Guan KL, Lambie EJ: Three genes of the MAP kinase cascade, mek-2, mpk-1/sur- 1 and let-60 ras, are required for meiotic cell cycle progression in Caenorhabditis elegans. Development 1995, 121(8):2525-35

47. Page BD, Guedes S, Waring D, Priess JR: The C. elegans E2F- and DPrelated proteins are required for embryonic asymmetry and negatively regulate Ras/MAPK signaling. Mol Cell 2001, 7(3451-460 [http:// download.cell.com/molecular-cell/pdf/PIIS1097276501001939.pdf].

48. Lahl V, Sadler B, Schierenberg E: Egg development in parthenogenetic nematodes: variations in meiosis and axis formation. Int J Dev Biol 2006, 50(4):393-8

49. Kosinski M, McDonald K, Schwartz J, Yamamoto I, Greenstein D: C. elegans sperm bud vesicles to deliver a meiotic maturation signal to distant oocytes. Development 2005, 132(15):3357-69.

50. Haaf A, Butler PJ, Kent HM, Fearnley IM, Roberts TM, Neuhaus D, Stewart $M$ : The motile major sperm protein (MSP) from Ascaris suum is a symmetric dimer in solution. J Mol Biol 1996, 260(2):251-60.

51. Normark B, Judson O, Moran N: Genomic signatures of ancient asexual lineages. Biol J Lin Soc 2003, 79:69-84. 
52. Klass MR, Kinsley S, Lopez LC: Isolation and characterization of a spermspecific gene family in the nematode Caenorhabditis elegans. Mol Cell Biol 1984, 4(3):529-37.

53. Ward S, Burke DJ, Sulston JE, Coulson AR, Albertson DG, Ammons D, Klass $M$, Hogan E: Genomic organization of major sperm protein genes and pseudogenes in the nematode Caenorhabditis elegans. J Mol Biol 1988, 199:1-13.

54. Scott AL, Dinman J, Sussman DJ, Yenbutr P, Ward S: Major sperm protein genes from Onchocerca volvulus. Mol Biochem Parasitol 1989, 36(2):119-26.

55. Novitski CE, Brown S, Chen R, Corner AS, Atkinson HJ, McPherson MJ: Major Sperm Protein Genes from Globodera rostochiensis. J Nematol 1993, 25(4):548-54.

56. Hojas RM, Post RJ: Regional genetic variation in the major sperm protein genes of Onchocerca volvulus and Mansonella ozzardi (Nematoda: Filarioidea). Int J Parasitol 2000, 30(14):1459-65.

57. Hoglund J, Engstrom A, Morrison DA, Mineur A, Mattsson JG: Limited sequence variation in the major sperm protein 1 (MSP) gene within populations and species of the genus Dictyocaulus (Nematoda). Parasitol Res 2008, 103:11-20.

58. Breathnach R, Benoist C, O'Hare K, Gannon F, Chambon P: Ovalbumin gene: evidence for a leader sequence in $\mathrm{MRNA}$ and DNA sequences at the exon-intron boundaries. Proc Natl Acad Sci USA 1978, 75(10):4853-7.

59. Rogozin IB, Sverdlov AV, Babenko VN, Koonin EV: Analysis of evolution of exon-intron structure of eukaryotic genes. Brief Bioinform 2005, 6(2):118-34

60. Abad P, Gouzy J, Aury JM, Castagnone-Sereno P, Danchin EG, Deleury E, Perfus-Barbeoch L, Anthouard V, Artiguenave F, Blok VC, Caillaud MC, Coutinho PM, Dasilva C, De Luca F, Deau F, Esquibet M, Flutre T, Goldstone JV, Hamamouch N, Hewezi T, Jaillon O, Jubin C, Leonetti P, Magliano M, Maier TR, Markov GV, McVeigh P, Pesole G, Poulain J, Robinson-Rechavi M, Sallet E, Segurens B, Steinbach D, Tytgat T, Ugarte E, van Ghelder C, Veronico P, Baum TJ, Blaxter M, Bleve-Zacheo T, Davis EL, Ewbank JJ, Favery B, Grenier E, Henrissat B, Jones JT, Laudet V, Maule AG, Quesneville H, Rosso MN, Schiex T, Smant G, Weissenbach J, Wincker P: Genome sequence of the metazoan plant-parasitic nematode Meloidogyne incognita. Nat Biotechnol 2008, 26(8):909-15

61. Opperman CH, Bird DM, Williamson VM, Rokhsar DS, Burke M, Cohn J, Cromer J, Diener S, Gajan J, Graham S, Houfek TD, Liu Q, Mitros T, Schaff J, Schaffer R, Scholl E, Sosinski BR, Thomas VP, Windham E: Sequence and genetic map of Meloidogyne hapla: A compact nematode genome for plant parasitism. Proc Natl Acad Sci USA 2008, 105(39):14802-7.

62. Triantaphyllou AC: Oogenesis and the Chromosomes of the Parthenogenic Root-knot Nematode Meloidogyne incognita. $J$ Nematol 1981, 13(2):95-104

63. Triantaphyllou AC: Polyploidy and reproductive patterns in the rootknot nematode Meloidogyne hapla. J Morphol 1966, 118(3):403-13.

64. Lunt DH: Genetic tests of ancient asexuality in root knot nematodes reveal recent hybrid origins. BMC Evol Biol 2008, 8:194

65. Kozak M: Compilation and analysis of sequences upstream from the translational start site in eukaryotic mRNAs. Nucleic Acids Res 1984, 12(2):857-72

66. Kozak M: Point mutations define a sequence flanking the AUG initiator codon that modulates translation by eukaryotic ribosomes. Cell 1986, 44(2):283-92.

67. Kozak M: An analysis of 5'-noncoding sequences from 699 vertebrate messenger RNAs. Nucleic Acids Res 1987, 15(20):8125-48.

68. Nadarajan S, Govindan JA, McGovern M, Hubbard EJ, Greenstein D: MSP and GLP-1/Notch signaling coordinately regulate actomyosindependent cytoplasmic streaming and oocyte growth in C. elegans. Development 2009, 136(132223-2234 [http://dev.biologists.org/content/ 136/13/2223.full.pdf+html].

69. Whitaker M: Control of meiotic arrest. Rev Reprod 1996, 1(2):127-35.

70. Sackton KL, Buehner NA, Wolfner MF: Modulation of MAPK activities during egg activation in Drosophila. Fly (Austin) 2007, 1(4):222-7.

71. Hansen E, Buecher E, Yarwood E: Alteration of sex of Aphelenchus avenae in culture. Nematologica 1973, 19:113-116.

72. Triantaphyllous AP, Fisher JM: Gametogenesis in Amphimictic and Parthenogenetic Populations of Aphelenchus avenae. J Nematol 1976, 8(2):168-77
73. Baldwin JG, Hirschmann H: Comparative Fine Structure of the Stomatal Region of Males of Meloidogyne incognita and Heterodera glycines. J Nematol 1976, 8:1-17.

74. Eisenback JD, Hirschmann H: Morphological comparison of meloidogyne males by scanning electron microscopy. J Nematol 1980, 12:23-32.

75. Santos M, Zintzaras E, Szathmary E: Origin of sex revisited. Orig Life Evol Biosph 2003, 33(4-5):405-32.

76. Archetti M: Recombination and loss of complementation: a more than two-fold cost for parthenogenesis. J Evol Biol 2004, 17(5):1084-97.

77. Brenner S: The genetics of Caenorhabditis elegans. Genetics 1974 77:71-94.

78. Lahl V, Halama C, Schierenberg E: Comparative and experimental embryogenesis of Plectidae (Nematoda). Dev Genes Evol 2003, 213:18-27.

79. Skiba F, Schierenberg E: Cell lineages, developmental timing, and spatial pattern formation in embryos of free-living soil nematodes. Dev Biol 1992, 151(2):597-610

80. Finney M, Ruvkun G: The unc-86 gene product couples cell lineage and cell identity in C. elegans. Cell 1990, 63(5):895-905.

81. Chan TA, Chu CA, Rauen KA, Kroiher M, Tatarewicz SM, Steele RE: Identification of a gene encoding a novel protein-tyrosine kinase containing SH2 domains and ankyrin-like repeats. Oncogene 1994, 9(4):1253-9.

82. Bektesh S, Van Doren K, Hirsh D: Presence of the Caenorhabditis elegans spliced leader on different mRNAs and in different genera of nematodes. Genes Dev 1988, 2(10):1277-83.

83. Johnstone IL: Molecular biology. In C. elegans. Practical approach series Oxford University Press; 1999.

84. Ewing B, Green P: Base-calling of automated sequencer traces using phred. II. Error probabilities. Genome Res 1998, 8(3):186-94.

85. Gordon D, Abajian C, Green P: Consed: a graphical tool for sequence finishing. Genome Res 1998, 8(3):195-202.

86. Rice P, Longden I, Bleasby A: EMBOSS: the European Molecular Biology Open Software Suite. Trends Genet 2000, 16(6):276-7.

87. Altschul S, Gish W, Miller W, Myers E, Lipman D: Basic local alignment search tool. J Mol Biol 1990, 215(3):403-10.

88. Rutherford K, Parkhill J, Crook J, Horsnell T, Rice P, Rajandream M, Barrell B: Artemis: sequence visualization and annotation. Bioinformatics 2000, 16(10):944-5.

89. Edgar R: MUSCLE: a multiple sequence alignment method with reduced time and space complexity. BMC Bioinformatics 2004, 5:113.

90. Galtier N, Gouy M, Gautier C: SEAVIEW and PHYLO_WIN: two graphic tools for sequence alignment and molecular phylogeny. Comput App / Biosci 1996, 12(6):543-8

91. Beitz E: TEXshade: shading and labeling of multiple sequence alignments using LATEX2 epsilon. Bioinformatics 2000, 16(2):135-9.

92. Abascal F, Zardoya R, Posada D: ProtTest: selection of best-fit models of protein evolution. Bioinformatics 2005, 21(9):2104-5.

93. Guindon S, Gascuel O: A simple, fast, and accurate algorithm to estimate large phylogenies by maximum likelihood. Syst Biol 2003, 52(5):696-704

94. Felsenstein J: PHYLIP (Phylogeny Inference Package) version 3.6. Distributed by the author 2005.

doi: $10.1186 / 1471-213 X-10-51$

Cite this article as: Heger et al., Conservation of MAP kinase activity and MSP genes in parthenogenetic nematodes BMC Developmental Biology 2010, 10:51 